\title{
COMPORTAMENTO PRODUTIVO DA VIDEIRA 'NIAGARA ROSADA' EM DIFERENTES SISTEMAS DE CONDUÇÃO, COM E SEM COBERTURA PLÁSTICA, DURANTE AS SAFRAS DE INVERNO E DE VERÃO ${ }^{1}$
}

\author{
JOSÉ LUIZ HERNANDES², MÁRIO JOSÉ PEDRO JÚNIOR ${ }^{3}$, \\ GABRIEL CONSTANTINO BLAIN ${ }^{4}$ GLAUCO DE SOUZA ROLIM ${ }^{5}$
}

RESUMO - Na região de Jundiaí (SP), os produtores de uva de mesa utilizam principalmente a cultivar Niagara Rosada. Atualmente, para aumentar a renda, o viticultor usa algumas alternativas tecnológicas que têm sido preconizadas, como o cultivo em manjedoura na forma de $\mathrm{Y}$, em substituição ao sistema de condução em espaldeira; a poda extemporânea que permite duas safras por ano (de verão e de inverno) e o uso de cobertura plástica para a proteção dos cachos contra intempéries e doenças. Portanto, foi desenvolvido um experimento visando a caracterizar a influência do sistema de condução, do uso de cobertura plástica e da poda extemporânea na produção e no tamanho dos cachos de 'Niagara Rosada'. Os resultados obtidos durante as safras de verão (2008 e 2009) e de inverno (2009 e 2010) permitiram verificar que, no sistema de condução em $\mathrm{Y}$, foram obtidas maiores produções e tamanho de cacho em relação ao espaldeira. $\mathrm{O}$ uso de cobertura plástica no sistema em Y propiciou aumento de produção devido ao incremento em número e massa dos cachos. Também foi verificado que tanto a produção quanto a massa do cacho foram superiores na safra de verão em comparação à de inverno.

Termos para indexação: uva de mesa, produção, massa do cacho, cultivo protegido, Vitis $s p$.

\section{EVALUATION OF VERTICAL AND "Y" TRAINING SYSTEMS AND OVERHEAD PLASTIC COVER ON 'NIAGARA ROSADA' GRAPE YIELD, DURING SUMMER AND WINTER GROWING SEASONS}

\begin{abstract}
The Niagara Rosada is the most important table grape cultivar for growers from Jundiaí region (São Paulo, Brazil). Currently, aiming to increase the grower benefit some technological alternatives have been recommended such as training system in a Y shape on replacement to unilateral single cordon with three vertical catch wires; application of off-season pruning that allows to obtain two harvests per year (summer and winter) and the use of plastic overhead cover to protect the vine's clusters against hailstorm and diseases occurrence. Therefore a field trial was carried out aiming to characterize the influence of the "Y" trellis system and the use of plastic overhead cover on yield and cluster size of 'Niagara Rosada' table grape. The obtained results during the growing seasons: summer (2008 and 2009) and winter (2009 and 2010) showed that the $\mathrm{Y}$ shaped system allows obtaining higher yields and larger size of clusters when compared to the vertical trellis system. The plastic overhead cover on the $\mathrm{Y}$ shaped system increased yield and cluster weight. It was also found that yield and cluster weight were higher for the summer growing season when compared to the winter crop.
\end{abstract}

Index terms: table grape, yield, bunch weight, protected cultivation, Vitis $s p$.

\footnotetext{
${ }^{1}$ (Trabalho 183-12). Recebido em: 06-06-2012. Aceito para publicação em: 29-11-2012.

${ }^{2}$ Biólogo MS., PqC Centro de Fruticultura, IAC, Jundiaí, SP, Brasil. E-mail: jlhernandes@iac.sp.gov.br

${ }^{3}$ Eng. Agr. Dr., Centro de Ecofisiologia e Biofísica, IAC, Campinas-SP. Brasil. Bolsista CNPq. E-mail: mpedro@iac.sp.gov.br

${ }^{4}$ Eng. Agr. Dr., Centro de Ecofisiologia e Biofísica, IAC, Campinas-SP. Brasil. E-mail: gabriel@iac.sp.gov.br

${ }^{5}$ Eng. Agr. Dr., Centro de Ecofisiologia e Biofísica, IAC, Campinas-SP. Brasil. E-mail: glaucorolim@gmail.com
} 


\section{INTRODUÇÃO}

A viticultura da região de Jundiaí está baseada na cultivar 'Niagara Rosada' conduzida em espaldeira com cordão esporonado único. Além disso, a maioria dos viticultores realiza a poda no início do segundo semestre, visando à obtenção da colheita no final do ano.

Recentemente, algumas alternativas tecnológicas vêm sendo disponibilizadas ao viticultor, possibilitando o aumento da rentabilidade e a melhoria da qualidade do produto. Dentre elas, o sistema de condução em forma de manjedoura em ' $\mathrm{Y}$ ' tem sido utilizado nas diferentes áreas vitícolas do País (CHAVARRIA et al., 2007; MOTA et al., 2008). Esse sistema de condução, apesar do maior custo inicial, proporciona altas produtividades e uvas com cachos de maior massa em relação ao sistema de condução em espaldeira (PEDRO JÚNIOR et al., 2011b). Além disso, facilita a adoção do cultivo protegido, seja pelo uso de cobertura com plástico impermeável, seja de telados plásticos.

$\mathrm{O}$ uso de cobertura plástica tem propiciado a obtenção de produto de melhor qualidade (PEDRO JÚNIOR et al., 2011a), minimizando o efeito das condições adversas do tempo (MOTA et al., 2008) e diminuindo a incidência de doenças com consequente diminuição do uso de defensivos agrícolas (CHAVARRIA et al., 2007; DETONI et al., 2007; PEDRO JÚNIOR et al., 2011a), e aumentado a produtividade (CHAVARRIA et al., 2009). Por outro lado, em Minas Gerais, Ferreira et al. (2004) observaram menor produtividade e teor de sólidos solúveis nas plantas protegidas, em comparação às conduzidas a céu aberto.

Outra tecnologia em uso na região diz respeito à poda extemporânea que, realizada em janeiro-fevereiro, permite a colheita durante meses de baixa ocorrência de chuvas (maio-junho), propiciando ao viticultor uma segunda safra, aumentando sua rentabilidade. $\mathrm{O}$ cultivo da videira em áreas tropicais possibilita a obtenção de duas ou mais safras por ano. Em Minas Gerais, Abrahão et al. (2002) avaliaram a produção extemporânea da 'Niagara Rosada', tendo verificado desenvolvimento satisfatório das brotações, tanto pelo vigor quanto pela carga de cachos, possibilitando uma segunda safra com cachos e bagas de menor tamanho, porém de excelente qualidade.

No sudoeste do Estado de Goiás, Neis et al. (2010) estudaram a produção e a qualidade da videira cultivar Niágara Rosada, em diferentes épocas de poda, concluindo que naquela região a uva pode ser podada em diferentes épocas e que a produtividade média é superior nas podas realizadas em março e abril. No Rio Grande do Sul, Souza e Fochesato (2007) concluíram que podas verdes efetuadas na 'Niagara Branca', em novembro, possibilitaram uma segunda safra entre março e abril, sendo uma alternativa de ampliação do período de oferta do produto.

Levando-se em consideração as possibilidades de aumento de produtividade, melhoria da qualidade dos cachos e obtenção de duas safras por ano, propiciadas pela utilização do sistema de condução em Y, pelo uso de cobertura plástica e pela poda extemporânea, foi desenvolvido este experimento em Jundiaí (SP), visando a comparar o comportamento produtivo e o tamanho dos cachos da videira 'Niagara Rosada' conduzida em espaldeira e em Y, com e sem cobertura plástica, durante as safras de verão (poda normal de inverno) e de inverno (poda extemporânea de verão).

\section{MATERIAL E MÉTODOS}

O experimento foi feito em vinhedos existentes em área experimental do Instituto Agronômico de Campinas (IAC/APTA/SAA), localizada em Jundiaí-

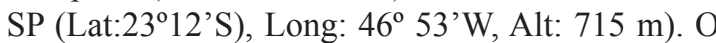
clima local, de acordo com Köppen, é classificado como $\mathrm{Cfa}$ para as regiões mais baixas e $\mathrm{Cfb}$ para as mais altas. De acordo com a normal climatológica (1961-1990), os valores de temperatura do ar e precipitação pluvial, durante as safras de inverno e verão, são, respectivamente, $20,2^{\circ} \mathrm{C}$ e $357 \mathrm{~mm} \mathrm{e}$ $21,6^{\circ} \mathrm{C}$ e $564 \mathrm{~mm}$. Para as safras de verão de 2008 e 2009 e de inverno de 2009 e 2010 , os valores médios de temperatura do ar foram $21,2^{\circ} \mathrm{C}, 22,2^{\circ} \mathrm{C}, 19,8^{\circ} \mathrm{C}$ e $19,5^{\circ} \mathrm{C}$, respectivamente. Nos mesmos períodos, os totais de precipitação foram de $374 \mathrm{~mm}, 818 \mathrm{~mm}$, $260 \mathrm{~mm}$ e $299 \mathrm{~mm}$, respectivamente.

Os tratos culturais, como: capina, remoção dos brotos apicais e laterais (desponte e desnetamento), adubação e controle semanal de doenças fúngicas, nas plantas sem cobertura plástica, foram feitos seguindo as práticas recomendadas para a região, enquanto para as videiras sob cobertura plástica foram feitas seis pulverizações durante o ciclo da planta.

Os sistemas de condução avaliados foram: espaldeira (ESP) e manjedoura em forma de Y sem (Y) e com cobertura de plástico (YPLA). O sistema de condução em espaldeira com cordão esporonado simples (Figura 1a) é um sistema de condução de baixo custo de implantação pelo viticultor, no qual os ramos da videira ficam dispostos na forma vertical (tipo renque). Os suportes para os fios de 
arame são mourões de madeira que ficam na linha das plantas, onde são fixados três fios de arame para condução vertical dos ramos do ano (de produção). O sistema de condução em manjedoura em forma de ' $Y$ ' utilizado foi uma adaptação, sendo as videiras conduzidas a céu aberto (Figura 1b) e com cobertura de filme plástico de polietileno de baixa densidade e 150 micras de espessura no sentido das ruas (Figura $1 \mathrm{c})$.

Poda curta foi realizada nas videiras nas safras de verão, em 13-08-08 e 26-08-2009 e de inverno em 04-02-2009 e 11-02-2010. Na área experimental, foram escolhidas ao acaso 20 plantas nas quais foram avaliados os seguintes parâmetros fitotécnicos: produção, número de cachos, massa, comprimento, largura dos cachos, obtidos na época da colheita: para a safra de verão, em 23-12-2008 e 27-12-2009 e para a de inverno, em 10-06-2009 e 13-06-2010. Foi realizado o registro do acúmulo de sólidos solúveis ao longo da maturação, utilizando refratômetro manual, e os cachos foram colhidos no ponto de colheita comercial (em torno de $14^{\circ} \mathrm{Brix}$ ). A produção de plantas individuais e a massa dos cachos foram medidas com balança de precisão de $1 \mathrm{~g}$ e $0,1 \mathrm{~g}$, respectivamente.

$\mathrm{O}$ delineamento experimental foi o inteiramente casualizado, com parcelas subdivididas no tempo (safra), e os tratamentos avaliados (sistema de condução) foram: espaldeira, manjedoura na forma de $\mathrm{Y}$ sem cobertura plástica e manjedoura na forma de Y com cobertura plástica. Em todos os tratamentos, o espaçamento utilizado foi de 1 metro entre plantas e dois metros entre linhas, com cada planta ocupando $2 \mathrm{~m}^{2}$, e população em torno de 5.000 plantas.ha ${ }^{-1}$. Os contrastes das médias amostrais foram analisados pelo teste de Tukey, a 5\% de significância.

\section{RESULTADOS E DISCUSSÃO}

Os dados de produção por planta, massa e número de cachos, comprimento e largura dos cachos para a 'Niagara Rosada', durante as safras de verão e de inverno para os diferentes sistemas de condução, estão apresentados na Tabela 1.

Produção: Os resultados obtidos de produção variaram entre 1,81 e 5,01 kg.planta ${ }^{-1}$ em função da safra e do sistema de condução. Durante a safra de verão de 2008, foi obtida a maior produção para a 'Niagara Rosada' (5,01 kg.planta-1), para o sistema de condução YPLA (Tabela 1), enquanto o menor valor $\left(1,81 \mathrm{~kg}\right.$.planta $\left.{ }^{-1}\right)$ foi observado para o sistema espaldeira, durante a safra de inverno de 2010.
Também, pode ser visto na Tabela 1 que as produções do sistema Y e YPLA foram superiores às da ESP. Os valores médios variaram entre 4,51 e $5,01 \mathrm{~kg}$.planta ${ }^{-1}$, durante as safras de verão. Durante o período de inverno, quando as diferenças foram mais acentuadas, as produções no YPLA variaram entre 2,84 e 4,43 kg.planta ${ }^{-1}$. Em comparação, para o sistema em espaldeira, foram obtidas para a safra de verão produções entre 2,68 e 3,78 kg.planta ${ }^{-1}$ e para a safra de inverno, entre 1,81 e 2,22 kg. planta $^{-1}$. Foi observado que as videiras conduzidas em Y sob cobertura plástica apresentaram maiores produções em comparação às conduzidas sem cobertura de plástico, independentemente de ser ciclo de verão ou de inverno. Na Tabela 1, pode ser verificado que, na safra de inverno de 2010, apesar de não ter sido observada diferença estatística entre os tratamentos $Y$ e YPLA, o valor da produção do YPLA foi superior ao do $\mathrm{Y}$ em cerca de $8 \%$.

A produtividade das videiras pode ser aumentada quando cultivada em ambiente protegido. No caso da videira 'Niagara Rosada', o uso de cobertura plástica no sistema de condução em Y propiciou aumento de produção entre 8 e $21 \%$ em função do ano agrícola. Como não houve diferença de espaçamento e de população de plantas nos diferentes sistemas de condução, os maiores valores de produção no sistema de condução em Y foram influenciados principalmente pela massa e pelo número de cachos, geralmente mais elevados quando em comparação ao sistema em espaldeira. Ainda, a cobertura plástica, por evitar a incidência direta de chuvas nos cachos, propicia melhores condições ambientais e, principalmente, facilita o controle de doenças fúngicas, induzindo a maiores produções (CHAVARRIA et al., 2007; DETONI et al., 2007; CHAVARRIA et al., 2009; PEDRO JÚNIOR et al., 2011a).

Deve-se salientar que o tipo de poda (curta) permitiu que a quantidade de gemas por planta fosse praticamente igual nas safras avaliadas. Portanto, as maiores produções no sistema em YPLA, como observado por Chavarria et al. (2009), além da massa e do tamanho do cacho, foram obtidas por a maior brotação de gemas estar relacionada a um maior aporte de reservas propiciado pelo cultivo protegido, uma vez que as folhas permanecem nas plantas por mais tempo.

De maneira geral, foram verificadas também maiores produções na safra de verão em relação à safra de inverno. Durante a safra de verão, considerando-se os anos agrícolas avaliados, em média, para os diferentes sistemas de condução, obtiveram-se 4,0 kg.planta ${ }^{-1}$, enquanto para a safra de 
inverno a produção média foi de $2,3 \mathrm{~kg}$.planta ${ }^{-1}$. Os maiores valores de produção para a 'Niagara Rosada' foram influenciados principalmente pelo tamanho do cacho, pois os valores de massa do cacho foram superiores durante a safra de verão em relação à de inverno.

A produtividade estimada para os diferentes sistemas de condução e safras está apresentada na Figura 2a. Verificou-se que, para o YPLA, as produtividades variaram entre 15 e 25 t.ha $^{-1}$, enquanto para o tratamento ESP, para o qual se obtiveram os menores valores, variaram entre 10 e 20 t.ha $^{-1}$.

Em resumo, os valores de produção obtidos para os diferentes tratamentos e safras permitiram verificar que as produções durante a safra de verão são superiores às de inverno; que o sistema de condução em Y é mais produtivo que ESP, e, ainda, que o uso de cobertura plástica permite obtenção de maiores produções.

Massa do cacho. Os valores médios de massa do cacho obtidos variaram entre 143,6 e 294,6 g para os diferentes tratamentos e anos agrícolas. Foi observado que, durante a safra de verão, os valores de massa de cacho foram superiores aos obtidos durante a safra de inverno (Figura 2b). Durante a safra de verão, os valores de massa dos cachos foram em média de $249 \mathrm{~g}$, enquanto na safra de inverno foram de 164 g. Na Tabela 1, observa-se que houve diferença entre os valores de massa do cacho para os diferentes tratamentos dentro da mesma safra, excetuando-se a safra de verão de 2008. Neis et al. (2010) observaram que, em Aparecida do Rio Doce (GO), a massa dos cachos da videira 'Niagara Rosada' podada no mês de julho foi de 206,3 g, enquanto para poda realizada no mês de março, a massa dos cachos foi inferior, em torno de $188 \mathrm{~g}$. Também, Anzanelo et al. (2010) obtiveram, para a 'Niagara Rosada', cachos com massa média entre 72 e $77 \mathrm{~g}$ para videiras podadas em novembro e dezembro, contra 152 a 157 g para aquelas podadas em julho e agosto, em Eldorado do Sul-RS. Hernandes et al. (2011), em cultivo de Niagara Rosada no sistema de condução em Y, em Louveira-SP, obtiveram cachos com massa entre 296 e $310 \mathrm{~g}$ na poda de inverno, enquanto na poda de verão a massa dos cachos variou entre 224 e 265 g.

Os resultados obtidos neste trabalho, associados àqueles encontrados na bibliografia, mostram que, independentemente da região produtora, a safra de inverno da Niagara Rosada tende a produzir cachos de menor massa. Esta redução da massa dos cachos, provavelmente, esteja relacionada à menor quantidade de reservas nos tecidos das gemas, em função de a poda ser realizada em ramos verdes que ainda não concluíram seu ciclo vegetativo, resultando em cachos com menor número de bagas e bagas menores. Déficit hídrico na fase de crescimento da baga, que pode ocorrer nestas regiões produtoras, na poda de verão, também pode contribuir para a redução do tamanho da baga.

Em relação à diferença na massa dos cachos devida ao sistema de condução, foi verificado que, na safra de verão de 2008, não houve diferença estatística, enquanto nas safras de verão de 2009 e de inverno de 2009 e 2010, a maior massa dos cachos no sistema de condução em Y, principalmente durante a safra de inverno, foi estatisticamente diferente do ESP. Pedro Júnior et al. (2011b), em Louveira-SP, mostraram que a massa dos cachos no sistema em Y sob telado plástico teve valores superiores ao espaldeira em cerca de $10 \%$. Tais dados indicam que o sistema de condução em Y pode contribuir par a melhoria dos cachos da 'Niagara Rosada' na safra extemporânea.

Outro aspecto avaliado foi a influência do uso de cobertura plástica no sistema em Y. Verificouse que apenas na safra de verão de 2008 não houve diferença estatística entre os valores médios de massa dos cachos, porém os maiores resultados foram obtidos quando se usou cobertura plástica. De maneira geral, foi observada uma tendência em se obter maiores valores de massa do cacho nas plantas conduzidas em YPLA.

Número de cachos: O número de cachos no sistema em Y foi estatisticamente superior ao ESP, variando entre 15 e 22 no Y com e sem plástico e entre 11 e 15 cachos por planta no ESP. Apesar de ter sido usada a poda curta em todos os tratamentos, foi obtido maior número de cachos no $\mathrm{Y}$ em relação ao sistema em ESP, principalmente no YPLA. O aumento do número de cachos no $\mathrm{Y}$ pode estar relacionado ao microclima propiciado pelo sistema de condução das plantas, uma vez que, segundo Shikhamany (1999), este influencia na incidência de luz solar nas gemas. Nas videiras conduzidas no sistema em "Y", resultam copas abertas, com ramos orientados em diagonal, permitindo-se maior incidência de luz nas gemas, resultando em aumento no número de cachos. Também, VIEIRA et al. (2006) verificaram que a fertilidade das gemas é maior em videiras conduzidas no sistema de pérgula (disposição horizontal dos ramos) do que em espaldeira (disposição vertical).

Além disso, foi verificado que o uso de cobertura plástica no Y não influenciou sobre o número de cachos, pois os valores médios dos sistemas de condução em Y sem e com cobertura plástica não diferiram estatisticamente entre si, seja 
na safra de verão, seja na de inverno.

Comprimento e largura do cacho: durante a safra de verão, tanto o comprimento quanto a largura dos cachos tiveram uma tendência em serem maiores que na safra de inverno, portanto o viticultor deve esperar cachos de menor tamanho na safra de inverno.

Durante a safra de verão, o comprimento dos cachos variou entre 11,0 a $13,6 \mathrm{~cm}$, enquanto para a safra de inverno foi entre 10,6 a $12,6 \mathrm{~cm}$. A mesma tendência foi observada para a largura dos cachos, tendo sido observados valores entre 6,6 e 7,6 $\mathrm{cm}$ para a safra de verão e entre 5,5 e $6,5 \mathrm{~cm}$ para a safra de inverno.

Maturação: conforme se pode observar na Figura 3, os diferentes sistemas de condução não influenciaram de maneira diferenciada ao longo da maturação da videira 'Niagara Rosada', com valores de sólidos solúveis confundindo-se entre sistemas de condução e épocas de poda, e permitiram maturação normal da videira, independentemente de safra de verão ou de inverno, com a colheita ao redor de 14 graus Brix, considerado índice comercial para esta cultivar.

De maneira geral, o uso de cobertura plástica no sistema de manjedoura em Y mostrou-se interessante por levar à produção de cachos maiores mesmo durante a safra de inverno. Segundo Chavarria et al. (2009), o aumento do comprimento do cacho no cultivo sob plástico pode estar relacionado à diminuição da radiação fotossinteticamente ativa, na área coberta, reduzindo a compactação. Em função disso, o engaço desses cachos também apresenta massas superiores ao cultivo convencional. Além disso, os cachos produzidos em ambiente protegido apresentam maior número de bagas.

Aliada às vantagens quantitativas e qualitativas de produção no cultivo protegido, a garantia das safras é a maior justificativa para o investimento nessa tecnologia de proteção das videiras. Dessa forma, em regiões onde é frequente a ocorrência de ventos e chuvas fortes, assim como a ocorrência de granizo durante o ciclo vegetativo/ produtivo, o emprego da cobertura apresenta-se como uma garantia. Isso porque a ocorrência dessas intempéries meteorológicas pode promover a perda total de uma safra, podendo, ainda, afetar o ciclo seguinte, como no caso do granizo, que danifica não só as folhas, mas também os ramos herbáceos e, com isso, a produção de reservas de carbono que seriam utilizadas na retomada do crescimento, na primavera, no próximo ciclo.

Outro aspecto relevante no cultivo protegido da videira diz respeito à redução do número de aplicações de fungicidas, sem prejuízo da produção (CHAVARRIA et al., 2007; PEDRO JÚNIOR et al., 2011a). Além da economia em defensivos, deve-se acrescentar a economia em mão de obra, combustíveis e desgastes de equipamentos, que influenciarão na redução do custo de produção da uva, ademais dos ganhos ambientais e de saúde humana, corroborando a busca de sistemas produtivos em consonância à sustentabilidade e segurança alimentar.

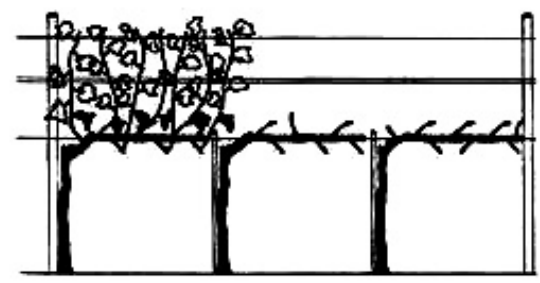

(a)

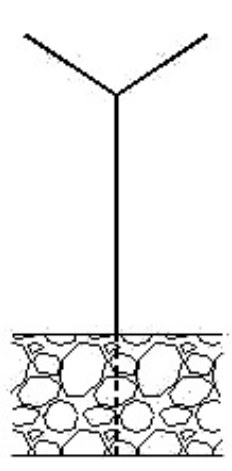

(b)

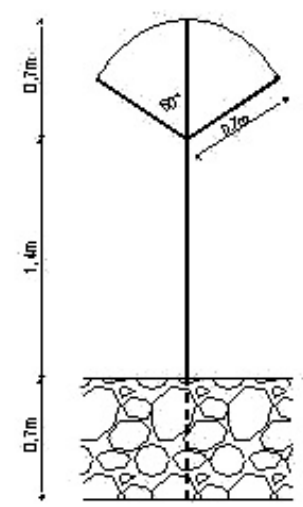

(c)

FIGURA 1- Sistema de condução da videira 'Niagara Rosada' em espaldeira com cordão esporonado simples (a) e manjedoura em forma de Y, sem (b) e com cobertura de plástico (c). 
TABELA 1- Valores médios de produção, massa do cacho, número de cachos e comprimento e largura dos cachos para as cultivares Niagara Rosada conduzida em espaldeira e em manjedoura, em forma de Y, com e sem cobertura plástica, nas safras de verão e de inverno, em Jundiaí (SP).

\begin{tabular}{lccccc}
\hline \multirow{2}{*}{ Variável } & Sistema de & \multicolumn{4}{c}{ Safra } \\
\cline { 3 - 6 } & condução & Verão/2008 & Inverno/ 2009 & Verão /2009 & Inverno/ 2010 \\
\hline \multirow{2}{*}{ Produção (kg.planta-1) } & Espaldeira & 3,78 a C & 2,22 bc C & 2,68 b C & 1,81 c B \\
& Y & 4,49 a B & 3,89 a,b B & 3,72 b B & 2,61 c A \\
& Y Plástico & 5,01 a A & 4,43 a A & 4,51 a A & 2,84 b A \\
\hline \multirow{2}{*}{ Massa do cacho (g) } & Espaldeira & 244,6 a A & 145,1 b C & 234,5 a B & 143,6 b C \\
& Y & 241,2 a A & 177,2 b B & 233,6 a B & 163,0 b B \\
& Y Plástico & 249,2 b A & 206,5 c A & 294,6 a A & 189,3 c A \\
\hline \multirow{2}{*}{ Número de cachos(planta) } & Espaldeira & 15,5 a B & 15,0 a B & 11,1 b B & 12,3 b B \\
& Y & 18,6 b A & 21,7 a A & 15,8 bc A & 14,9 c A \\
& Y Plástico & 20,1 a A & 21,1 a A & 15,4 b A & 15,4 b A \\
\hline \multirow{2}{*}{ Comprimento do cacho (cm) } & Espaldeira & 13,6 a A & 10,6 b C & 11,7 b C & 11,0 b B \\
& Y & 13,0 a B & 11,1 b B & 12,5 a B & 11,3 b B \\
& Y Plástico & 12,8 ab B & 12,3 b A & 13,4 a A & 12,6 ab A \\
\hline \multirow{2}{*}{ Largura do cacho (cm) } & Espaldeira & 6,8 a A & 5,5 b B & 6,6 a C & 5,9 b B \\
& Y & 6,9 a A & 5,7 b B & 6,9 a B & 5,8 b B \\
& Y Plástico & 6,9 a A & 6,5 bc A & 7,6 a A & 6,2 a C \\
\hline
\end{tabular}

Médias seguidas da mesma letra, minúscula na horizontal (safra) e maiúscula na vertical (sistema de condução), não diferem entre si, pelo teste de Tukey, a $5 \%$ de probabilidade.
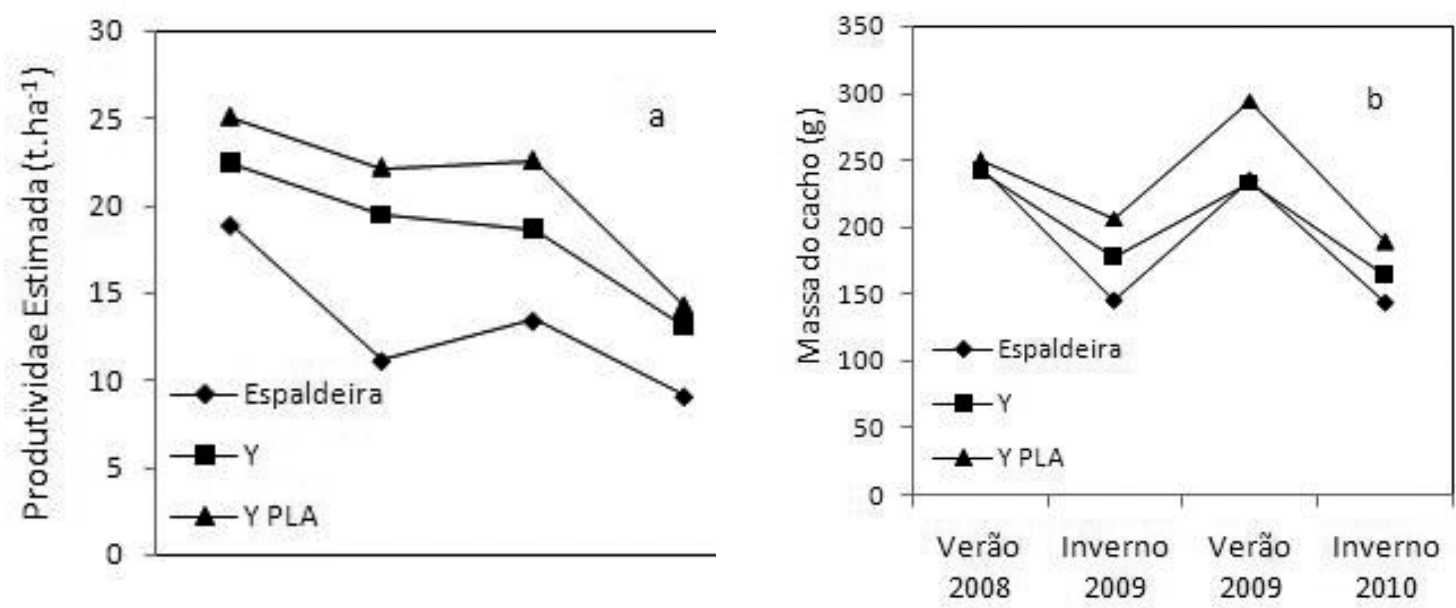

FIGURA 2-Produtividade estimada (a) e massa dos cachos (b) da videira 'Niagara Rosada' conduzida em espaldeira e em manjedoura, na forma de $\mathrm{Y}$ a céu aberto (Y) e com cobertura de plástico ( $\mathrm{Y}$ PLA), para as safras de verão e de inverno, em Jundiaí (SP). 

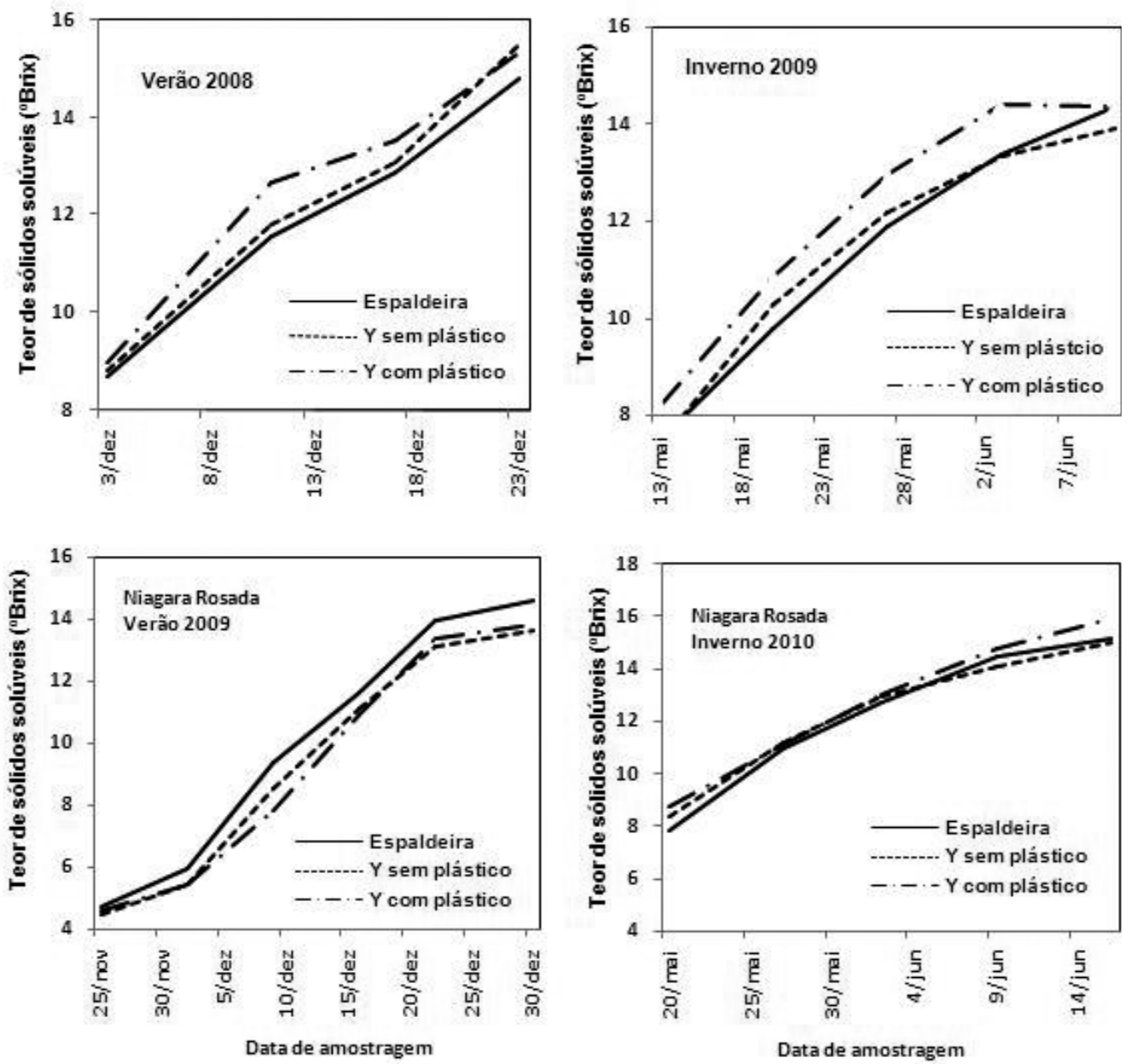

FIGURA 3 - Evolução do acúmulo de sólidos solúveis ( ${ }^{\circ}$ Brix) ao longo da maturação da videira 'Niagara Rosada' conduzida em espaldeira e em manjedoura, na forma de $\mathrm{Y}$ a céu aberto e com cobertura de plástico, para as safras de verão e de inverno, em Jundiaí (SP).

\section{CONCLUSÕES}

1-A comparação dos sistemas de condução em espaldeira e em manjedoura na forma de $\mathrm{Y}$ com e sem cobertura de plástico, para a videira 'Niagara Rosada', cultivada durante as safras de verão e de inverno, na região produtora de Jundiaí (SP), permite concluir que:

a) a produção foi maior durante a safra de verão em comparação à de inverno, para os diferentes sistemas de condução.

b) para o sistema de condução em Y, foram obtidas maiores produções em comparação à espaldeira, tanto durante as safras de verão quanto nas de inverno.

c) o uso de cobertura plástica no sistema em Y permite obtenção de maior produção e cachos com maior tamanho. d) o sistema de condução em manjedoura na forma de $\mathrm{Y}$, com ou sem cobertura plástica, não interferiu na maturação da 'Niagara Rosada'.

\section{REFERÊNCIAS}

ABRAHÃO, E.; ALVARENGA, A.A.; FRAGUAS, J.C.; REGINA, M.A.A; SILVA, V.J. Potencialidades do município de Lavras-MG para a produção extemporânea de uvas 'Niagara Rosada' para mesa. Ciência e Agrotecnologia, Lavras,v.26, n.4, p.865868, 2002.

ANZANELLO, R.; SOUZA, P.V.D.; COELHO, P.F. Uso de poda seca e da poda verde para obtenção de duas safras por ciclo vegetativo em três cultivares de videira. Revista Brasileira de Fruticultura, Jaboticabal, v.32, n.1, p.196-203, 2010. 
CHAVARRIA, G.; SANTOS, H.P.; SÔNEGO, O.R.; MARODIN, G.A.B.; BERGAMASCHI, H.; CARDOSO, L.S. Incidência de doença e necessidade de controle em cultivo protegido de videira. Revista Brasileira de Fruticultura, Jaboticabal, v.29, n.3, p.477-482, 2007.

CHAVARRIA, G.; SANTOS, H.P.; MANDELLI, F.; MARODIN, G.A.B.; BERGAMASCHI, H.; CARDOSO, L.S. Potencial produtivo de videiras cultivadas sob cobertura de plástico. Pesquisa Agropecuária Brasileira, Brasília, v.44, n.2, p.141147, 2009.

DETONI, A.M.; CLEMENTE, E.; FORNARI, C. Produtividade e qualidade da uva 'Cabernet Sauvignon' produzida sob cobertura de plástico em cultivo orgânico. Revista Brasileira de Fruticultura, Jaboticabal, v.29, n.3, p.530-534. 2007.

FERREIRA, E.A.; REGINA, M.A.R.; CHALFUN, M.J.; ANTUNES, L.E.C. Antecipação da safra para a videira 'Niagara Rosada' na região sul do Estado de Minas Gerais. Ciência e Agrotecnologia, Lavras, v.28, n.6, p.1221-1227, 2004.

HERNANDES, J.L.; PEDRO JÚNIOR, M.J.; BLAIN, G.C. Fenologia e produção da videira Niagara Rosada conduzida em manjedoura na forma de Y sob telado plástico, durante as safras de inverno e de verão. Revista Brasileira de Fruticultura, Jaboticabal, v. 33, p.499-504, 2011. Edição especial.

MOTA, C.S.; AMARANTE, C.V.T.; SANTOS, H.P.; ZANARDI, O.Z. Comportamento vegetativo e produtivo de videiras 'Cabernet Sauvignon' cultivadas sob cobertura plástica. Revista Brasileira de Fruticultura, Jaboticabal, v.30, n.1, p 148-153, 2008.
NEIS, S.; REIS, E.F.; SANTOS, S.C. Produção e qualidade da videira cv. Niágara Rosada em diferentes épocas de poda no sudoeste goiano. Revista Brasileira de Fruticultura, Jaboticabal, v. 32 , n. 4, p. 1146-1153, 2010

PEDRO JÚNIOR, M.J.; HERNANDES, J.L.; ROLIM, G.S. Sistema de condução em Y com e sem cobertura plástica: efeitos no microclima, produção, qualidade do cacho e ocorrência de doenças fúngicas na videira 'Niagara Rosada'. Bragantia, Campinas, v.70, n. 1, p.228-233, 2011 a.

PEDRO JÚNIOR, M. J.; HERNANDES, J. L.; ROLIM, G.S.; BLAIN, G. C. Microclima e produção da uva de mesa 'Niagara Rosada' conduzida em espaldeira a céu aberto e em manjedoura na forma de Y sob telado plástico. Revista Brasileira de Fruticultura, Jaboticabal, v. 33, p.511-518, 2011 b. Número especial.

SOUZA, P.V.; FOCHESATO, M.L. Emprego da poda verde para a obtenção de duas safras por ciclo vegetativo em 'Niagara Branca'. Bragantia, Campinas, v.66, n.4, p.611-616, 2007.

VIEIRA, C. R. Y. I.; PIRES, E. J. P.; TECCHIO, M. A.; OTSUBO, I. M. N.; VIEIRA, M. C.; YAMASAKI, A. K.; BORTOLANZA, O. Fertilidade de gemas de videiras 'Niagara Rosada' de acordo com o sistema de condução. Revista Brasileira de Fruticultura, Jaboticabal, 2006, vol.28, n.1, p. 136-138. 